\section{Evaluation of Treatment of Herniated Lumbar Disc Sciatica by Epidural Corticosteroid Injection}

\section{Abstract}

Background: Medical facilities in Vietnam both use Methylprednisolone acetate and Hydrocortisone acetate in treatment with different administrations. This study aimed to evaluate of effects and sideeffects of epidural injection of Methylprednisolone acetate and Hydrocortisone acetate in the treatment of herniated lumbar disc sciatica.

Methods and findings: Cross-sectional descriptive study on 120 herniated lumbar disc sciatica patients treated at Department of Orthopedic, 7A Military Hospital, Ho Chi Minh City, VietNam. The patients were divided into two groups in coupling fashion based on the Visual Analog Scale (VAS)score of pain.

Study results showed that both corticosteroid drugs (Methylprednisolone acetate and Hydrocortisone acetate) yielded good outcomes on all investigated parameters and there was no significant difference between the two medications $(p<0.05)$; administration of Methylprednisolone acetate reduced VAS score of $1.96 \pm 1.35$ points and Hydrocortisone acetate reduced of $2.12 \pm 1.19$ points. Lasegue test score in Methylprednisolone acetate administered patients raised from $75.73 \pm 19.12$ to $81.55 \pm 15.27$ and inHydrocortisone acetate patients from $71.35 \pm 10.21$ to $81.33 \pm 7.78$ ). Treatment methods were safe, and there was no difference in complication rates between the two groups. The direct and indirect cost of Hydrocortisone acetate administration was three times higher than Methylprednisolone acetate.

Conclusion: It was safe and effective to administrate both Methylprednisolone acetate and Hydrocortisone acetate in the treatment of herniated lumbar disc sciatica. Methylprednisolone acetate administration was more economical than Hydrocortisone acetate.
Quang-Tri Lê', Minh Hoang Nguyen ${ }^{1}$

1 Department of Orthopedics, 7A Military Hospital. 466 Nguyen Trai Street, Ward 8, District 5, Ho Chi Minh City, 72706, Viet Nam.

\section{Contact information:}

\section{Quang-Tri Lê.}

Address: Director of 7A Military Hospital. Head of Department of Orthopedics, Head of Department of High-Tech Diagnostics, 466 Nguyen Trai Street, Ward 8, District 5, Ho Chi Minh City, 72706, Viet Nam. Tel: (+084)0839241868.

\section{”- lqtri@ntt.edu.vn} tsbstri@yahoo.com

\section{Keywords \\ Sciatica; Epidural Injection; Methylprednisolone Acetate; Hydrocortisone Acetate.}




\section{Introduction}

Sciatica is a kind of lower back pain that irritates the sciatic nerve [1, 2]. The sciatic nerve is the longest nerve in the human body, running from the lower back through the back of the leg to the heel and sole of the foot. Sciatica has common symptoms such as lower back pain that expand to the hip and back of the leg $[3,4]$. Various problems might cause pressure or inflammation to the sciatic nerve, leading to sciatica, but one of the primary causes is disc herniation in the lumbar spine. A report in 2011 in Vietnam showed that disc herniation's rate of contract in the community is $0.64 \%[5,6]$.

The medication used in the treatment of sciatica are mainly analgesics (paracetamol, efferalgan codeine, di antalvic), anti-inflammatory (voltarel, tilcotil, mobic...), muscle relaxants (mydocalm, decontractyl, myonal...), epidural injections with hydrocortisone or methylprednisolone acetate, combined with hot and cold compresses [7, 8].

The epidural injection is the introduction of an appropriate dose of medication into the epidural space, also known as the space around the spinal cord. This activity will help patients with a herniated disc or some other bone and joint diseases reduce inflammation temporarily. The epidural method can also help patients improve the swelling and pain around the damaged nerves as well as inside or around the spinal nerve roots [9].

The Department of Orthopedics, 7A Military Hospital, and many other medical facilities in Vietnam both use Methylprednisolone acetate and Hydrocortisone acetate in treatment with different administration: Hydrocortisone acetate (HydrocortisoneLidocaine-Richter)thrice per treatment and Methylprednisolone acetate (Depo-Medrol) once.

This study aimed to evaluate the effects and side-effects of epidural injection in the treatment of herniated lumbar disc sciatica using two kinds of medication (Methylprednisolone acetate and Hydrocortisone acetate).

\section{Methods}

The study investigated 120 patients treated with both internal medication and external surgery at Department of Orthopedics, the 7A Military Hospital, Ho Chi Minh City, Viet Nam, from May 2015 to May 2017.

Criteria for selection were patients with clinical sciatic nerve pain, showing disc herniation at $L 4 / 5$ and L5S1 compressing against the horizontal nerve roots in lumbar spine MRI images, having no contraindication against corticoids and epidural injection, and volunteered to take part in the research.

The methods of study was cross-sectional descriptive prospective.

The patients were divided into two groups in coupling fashion based on Visual Analog Scale (VAS) score of pain.

Group 1 gotone time epidural injection of Methylprednisolone acetate (Depo-Medrol, Pfizer) 40mg.

Group 2 got epidural injection of Hydrocortisone acetate (Hydrocortisone-Lidocaine-Richter, Gedeon Richter). Each vial contained $05 \mathrm{ml}$, equivalent to $\mathrm{Hy}-$ drocortisone acetate $125 \mathrm{mg}$ and Lidocaine chloride $25 \mathrm{mg}$. The procedure included three injection times, once per 3 days, each time using $01 \mathrm{ml}$.

Both groups had similar accompanying treatment, including analgesia, non-steroid anti-inflammatory, and rehabilitation.

The effect of the two groups of medication was assessed via VAS pain score and movement rehabilitation tests such as the Lasegue test and the finger-floor test.

Safety was assessed via the degree of post-injection pain, allergic symptoms (itchiness, anaphylaxis shock), heart rate, blood pressure, and local/systemic infection (if any).

The economic aspect was assessed via direct and indirect costs such as medication cost, procedures cost, daily labor time lost for treatment time, transportation time for patients and assistants (if any), and working time spent by physicians. 


\section{Results}

\section{Patient general information}

The average age of patients was $54.2 \pm 12.5$ years (min. 25 and max. 86). Malepatients were 42.5\%, and females were $57.5 \%$.

Heavy laborers accounted for $62.5 \%$ of patients. Patients with onset factors (trauma, wrong exercise posture, etc.) accounted for $37.5 \%$ ofthe cases.

Several clinical traits and image diagnosis were described in Table 1.

Mechanical pain occurred in $83.3 \%$ of patients. Ninety-five patients (79.2\%) had pain relief posture. Signs of compressed nerve roots took place in 80 patients $(66.7 \%)$, and 89 patients had bell ring symptoms (74.2\%).

Patients were classified based on disc herniation location, as shown in Table 2. Multiple layered disc herniation occurred in 86 patients (71.7\%), mostly at the sites of L4-5, L5-S1 (35.0\%), then L3-4, L4-5, L5-S1 (20.8\%).

\section{Evaluation of effects and side-} effects of epidural injection using Methylprednisolone acetateor

\section{Hydrocortisone acetate}

Pain remedy and motion rehabilitation effect Comparison of pain remedy between Methylprednisolone acetateand Hydrocortisone acetate epidural injection was shown in Table 3.

After one month, the pain level, according to VAS score, was significantly reduced in both groups $(p<0.01)$. There was no difference between the two investigated groups $(p>0.01)$.
Table 1. Patients classification based on clinical traits.

\begin{tabular}{l|c|}
\multicolumn{1}{c|}{ Clinical traits } & $\%$ \\
\hline Pain characteristics & $03.3(04 / 120)$ \\
\hline Inflammatory & $83.3(100 / 120)$ \\
\hline Mechanical & $13.4(16 / 120)$ \\
\hline Both & $79.2(95 / 120)$ \\
\hline Pain remedy posture & $20.8(25 / 120)$ \\
\hline Yes & $66.7(80 / 120)$ \\
No & $33.3(40 / 120)$ \\
\hline Signs of compressed nerve roots (increased pain when \\
coughing, sneezing, contracting lower muscles) \\
\hline Yes \\
No \\
\hline Bell ring symptoms \\
\hline Yes \\
No
\end{tabular}

Table 2. Patients classification based on disc herniation location.

\begin{tabular}{|c|c|c|}
\hline \multicolumn{2}{|c|}{ Domains/Facets } & Natal \\
\hline \multicolumn{3}{|c|}{ Single layered } \\
\hline \multicolumn{2}{|l|}{ L3-4 } & $02.5(3 / 120)$ \\
\hline \multicolumn{2}{|l|}{ L4-5 } & $20.0(24 / 120)$ \\
\hline \multicolumn{2}{|l|}{ L5-S1 } & $05.8(7 / 120)$ \\
\hline \multicolumn{2}{|l|}{ Total } & $28.3(34 / 120)$ \\
\hline \multicolumn{3}{|c|}{ Multiple layered } \\
\hline \multirow{3}{*}{ 2-layered } & L3-4, L4-5 & $05,8(7 / 120)$ \\
\hline & L4-5, L5-S1 & $35.0(42 / 120)$ \\
\hline & Total & $40.8(49 / 120)$ \\
\hline \multirow{3}{*}{ 3-layered } & L2-3, L3-4, L4-5 & $4.2(5 / 120)$ \\
\hline & L3-4, L4-5, L5-S1 & $20.8(25 / 120)$ \\
\hline & Total & $25.0(30 / 120)$ \\
\hline \multirow{3}{*}{ 3-layered } & L2-3, L3-4, L4-5, L5-S1 & $05.8(7 / 120)$ \\
\hline & Total & $05.8(7 / 120)$ \\
\hline & Total & $71.7(86 / 120)$ \\
\hline \multicolumn{2}{|l|}{ Total } & $100(120 / 120)$ \\
\hline
\end{tabular}

Table 3. Pain level when administered with Methylprednisolone and Hydrocortisone according to VAS score.

\begin{tabular}{|c|c|c|c|c|}
\hline \multirow{2}{*}{$\begin{array}{l}\text { Medication } \\
\text { administered }\end{array}$} & \multirow{2}{*}{$\begin{array}{c}\text { Number } \\
\text { of } \\
\text { Patients }\end{array}$} & $\begin{array}{l}\text { Pre-administered } \\
\text { pain level }\end{array}$ & $\begin{array}{l}\text { Pain level one month } \\
\text { post-administration }\end{array}$ & $\begin{array}{l}\text { Efficiency variance (level of pain } \\
\text { reduction) after one month }\end{array}$ \\
\hline & & no & n 30 & n 30 \\
\hline Methylprednisolone & 60 & $5.78 \pm 1.58$ & $3.82 \pm 2.15$ & $1.96 \pm 1.35$ \\
\hline Hydrocortisone & 60 & $5.77 \pm 1.82$ & $3.63 \pm 1.62$ & $2.12 \pm 1.19$ \\
\hline
\end{tabular}


Table 3. Patients classification based on Lasegue test results.

\begin{tabular}{|c|c|c|c|c|}
\hline \multirow{3}{*}{ Lasegue test results } & \multicolumn{2}{|c|}{ Methylprednisolone } & \multicolumn{2}{|c|}{ Hydrocortisone } \\
\hline & Pre-administration & After 1 month & Pre-administration & After 1 month \\
\hline & $\%$ & $\%$ & $\%$ & $\%$ \\
\hline Very good > $80^{\circ}$ & $50.0(30 / 60)$ & $68.3(41 / 60)$ & $50.0(30 / 60)$ & $16.7(10 / 60)$ \\
\hline Good 60-80 & $36.7(22 / 60)$ & $23.3(14 / 60)$ & $38.3(23 / 60)$ & $81.7(49 / 60)$ \\
\hline Average $30-60^{\circ}$ & $13.3(8 / 60)$ & $8.4(5 / 60)$ & $11.7(7 / 60)$ & $1.6(1 / 60)$ \\
\hline No outome $<30^{\circ}$ & 0 & 0 & 0 & 0 \\
\hline Total & $100 \%(60 / 60)$ & $100 \%(60 / 60)$ & $100 \%(60 / 60)$ & $100 \%(60 / 60)$ \\
\hline Average score & $75.73 \pm 19.12$ & $81.55 \pm 15.27$ & $71.35 \pm 10.21$ & $82.33 \pm 7.78$ \\
\hline
\end{tabular}

Figure 1: Patients classification based on fingerfloor test.

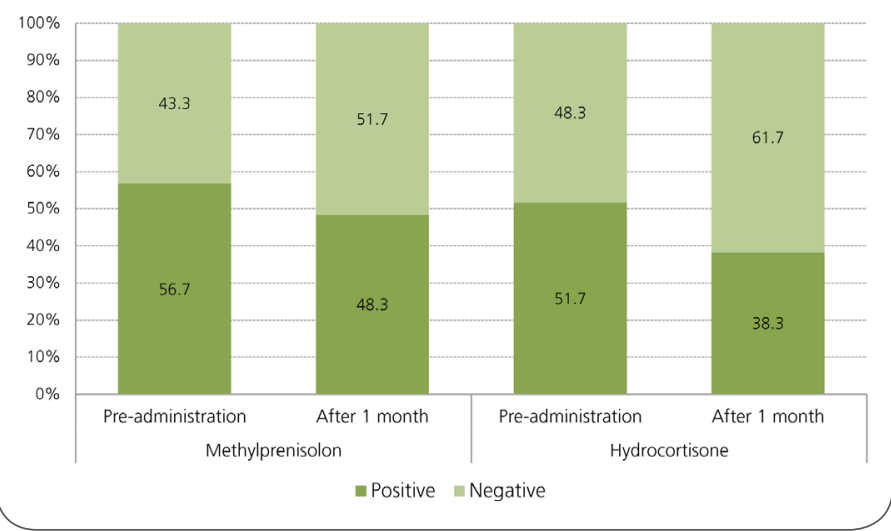

Figure 2: Cost comparison of epidural injection using Methylprednisolone and Hydrocortisone. "Other cost" included direct and indirect costs.

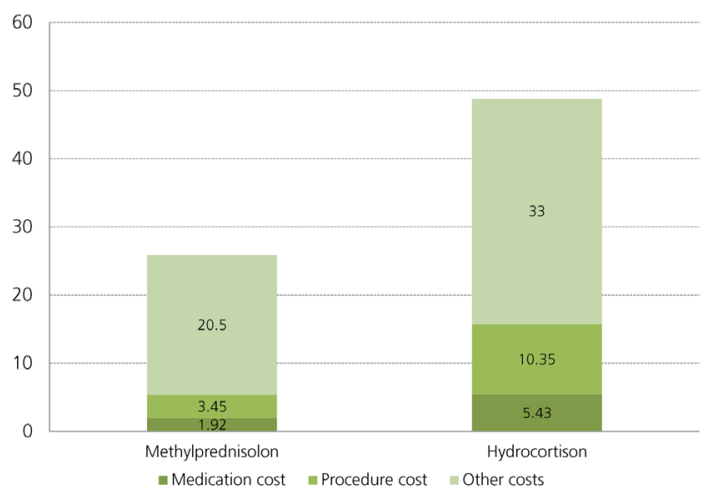

Lasegue test results was presented in Table 4.

Lasegue test score was significantly improved one month after administration in both groups ( $p<$ 0.01). There was no significant difference between the two groups $(p>0.01)$.

Finger-floor test was shown in Figure 1.

Finger-floor test outcomes one month after administration were significantly improved $(p<0.05)$. There was no significant difference between the two groups ( $p>0.01$ ).

\section{Treatment side-effects}

Amongst 120 patients, there was three patient felt increased pain after injection (2.5\%).

\section{The economic value of the methods}

The cost comparison of epidural injection of Methylprenisolone and Hydrocrotisone was presented in Figure 2. Treatment cost using Hydrocortisone was three times higher than using Methylprednisolone.

\section{Discussion}

Epidural injection therapy for the herniated disc has been used for a long time in the world. In Vietnam, this method has been applied for more than a decade and has a high success rate.

\section{Patient general information}

The average age and sex's information of studied patients were similar to other domestic researches 
[2-3], and career information in this study was also not different from other authors. Heavy laborers accounted for $62.5 \%$ of the patients, and these factors increase disc herniation risk [3].

Mechanical pain took place in $83.3 \%$ of the patients; 95 patients (79.2\%) had pain relief posture; 80 patients $(66.7 \%)$ showed clinical compressed nerve root signs BN; 89 patients (74.2\%) had typical bell ring symptoms. These results were compatible with earlier studies [3].

In this study, single-layered herniation made up of $28.3 \%$ cases, in which 24 patients $(20.0 \%)$ had herniation at L4-5 sites, seven patients (05.8\%) in L5-S1locations. Multiple-layered herniation made up of $71.7 \%$ cases. Similar to the results of Nguyen et al, (2016) [6], disc herniation usually occurred at L4-5 and L5-S1 since these sites are the fulcrum of the spine and are frequently burdened by the bodyweight; they also experienced the motions with the largest range; consequently injuries, microinjuries, and detrimental posture quickly lead to disc herniation occasionally happen in these sites [6-12].

\section{Effects, side-effects and economic efficiency of epidural injection using Methylprednisolone acetate or Hydrocortisone acetate}

\section{Pain remedy and movement rehabilitation effects of the two epidural injection methods}

Average VAS pain scores of Methylprednisolone administered patients were $5.78 \pm 1.58$ before injection and $3.82 \pm 2.15$ after injection; of Hydrocortisoneadministered patients were $5.77 \pm 1.82$ and $3.63 \pm 1.62$, respectively. Both patients group had significantly reduced VAS scores $(p<0.01)$, and no significant difference was observed between the groups ( $p>0.05$ ).

Lasegue test scores were improved similarly. Average Lasegue scores of Methylprednisolone administered patients were $75.73 \pm 19.12$ before injec- tion and $81.55 \pm 15.87$ at one month after injection; of Hydrocortisone administered patients were 71.35 \pm 10.21 và $82.33 \pm 7.78$ respectively. Both patients group had significantly increased Lasegue scores ( $p$ $<0.01)$, and no significant difference was observed between the groups ( $p>0.01$ ).

Amongst Methylprednisolone and Hydrocortisone administered group, $56.7 \%$ and $51.7 \%$ of the patients, respectively, failed to do the finger-floor test before administration. At one month after administration, these rates in Methylprednisolone and Hydrocortisone administered groupswere 48.3\% and $38.3 \%$, respectively. Therefore finger-floor test showed improvement in both groups ( $p<0.05$ ), and there was no significant difference between the groups $(p>0.01)$.

Pain remedy effects in this study were similar to other worldwide researches. Riewet al. (2006) showed that epidural corticosteroid injection had apparent analgesic effects compared with only bupivacaine administered patients ( $p=0.052)$, the rate of surgery also reduced [13-15].

\section{Epidural injection side effects}

The epidural injection might pose some risks of complications such as infection, itchiness, bleeding, anaphylaxis shock, and temporary or permanent nerve damage.

Three in 120 patients had increased pain after Methylprednisolone injection (2.5\%). None had allergic symptoms such as anaphylaxisshock or itchiness during and after administration. Nguyen et al. 2016 [6] reported that one patients (1.7\%) had post-administration increased pain, and no patient had anaphylaxis shock or infection at injected sites.

Epidural injection procedures at Department of Orthopedics, the 7A Military Hospital followed strict safety standards, especially the aseptic criteria; hence nonecomplication happened during the research. The studied method is considered reasonably safe. 


\section{Comparison of convenience and economic efficiency between epidural injection using Methylprednisolone acetate and Hydrocortisone acetate}

Medication cost: one vial of Methylprednisolone acetate (Depo-Medrol, Pfizer) 40mg, administered once, the cost was 1.92 USD. Meanwhile, three vials of Hydrocortisone acetate (Hydrocortisone-Lidocaine-Richter, Gedeon Richter), the expense was1.81 USDx $3=5.43$ USD.

Procedure cost: Hydrocortisone acetate was administrated thrice; therefore, it had tripled the cost of Methylprednisolone acetate (3.45 USD x $3=$ 10.35 USD).

Other indirect costs: Hydrocortisone acetate administration had tripled the cost of Methylprednisolone acetate due to three injections. In detail, waiting time, travel time (based on labor day cost), inconvenience, traffic accident risks, and infection risks during injection, etc. were tripled.

Methylprednisolone epidural injection average cost was $25 \pm 4.5$ USD; meanwhile, Hydrocortisone administration was $48 \pm 4.5$ USD, and the patients had to spendthree days to visit the hospital. Conclusivelyadministrated with Methylprednisolone was more economical than with Hydrocortisone.

\section{Conclusion}

Treatment of herniated lumbar disc sciatica by epidural injection with Methylprednisolone acetate and Hydrocortisone acetate was safe and effective. Methylprednisolone acetate administration was more economical than Hydrocortisone acetate.

\section{Declaration}

\section{Scientific Responsibility Statement}

The authors declare that they are responsible for the article's scientific content including study design, data collection, analysis and interpretation, writing, some of the main line, or all of the preparation and scientific review of the contents and approval of the final version of the article.

\section{Animal and human rights statement}

All procedures performed in this study were in accordance with the ethical standards of the institutional and/or national research committee and with the 1964 Helsinki declaration and its later amendments or comparable ethical standards.

\section{Funding}

None.

\section{Conflict of interest}

None of the authors received any type of financial support that could be considered potential conflict of interest regarding the manuscript or its submission.

\section{References}

1. Wang YC, Chiu YS, Yeh $\mathrm{CH}$. Leriche's syndrome presenting as sciatica. Ann Vasc Surg. 2010; 24(5):694.e1-e3.

2. Kim WH, Lee SH, Lee DY (2011). Changes in the cross-sectional area of multifidus and psoas in unilateral sciatica caused by lumbar disc herniation. J Korean Neurosurg Soc. 2011; 50(3):201204.

3. Ropper AH, Zafonte RD. Sciatica. N Engl J Med. 2015 Mar; 372(13):1240-8.

4. Valat JP, Genevay S, Marty M, Rozenberg S, Koes B. Sciatica. Best Pract Res Cl Rh. 2010; 24(2):241-252.

5. Nguyen Thi NL, Hoang HS, Nguyen VN. Several risk factors account for herniated disc sciatica in the community. Vietnam J Med. 2011 (Special Issue):58-63. (in Vietnamese).

6. Nguyen TNL, Dao XT, Do VA, Trần TG and Nguyen TNM. Evalutaion of epidural corticosteroid injection in treatment of lumbar disc herniation with radiculopathy. J Internal Med. 2016; 16(4): 12-19. (in Vietnamese)

7. Benoist M, Boulu P, Hayem G. Epidural steroid injections in the management of low-back pain with radiculopathy: an update of their efficacy and safety. Eur Spine J. 2012; 21(2):204-213.

8. Jordan JL, Konstantinou K, O'Dowd J. Herniated lumbar disc: injection interventions for sciatica. BMJ ClinEvid. 2016:1118. 
9. Chou R, Hashimoto R, Friedly J, Fu R, Bougatsos C, Dana T, Sullivan SD, Jarvik J.. Epidural Corticosteroid Injections for Radiculopathy and Spinal Stenosis: A Systematic Review and Meta-analysis. Ann Intern Med. 2015; 163(5):373-381. doi: 10.7326/M15-0934.

10. Arjmand N, Plamondon A, Shirazi-Adl A, Parnianpour M, Larivière C. (2012). Predictive equations for lumbar spine loads in load-dependent asymmetric one-and two-handed lifting activities. ClinBiomech. 2012; 27(6): 537-44.

11. Miwa S, Yokogawa A, Kobayashi T, Nishimura T, Igarashi K, Inatani H, Tsuchiya H. Risk Factors of Recurrent Lumbar Disk Herniation. J Spinal Disord Tech. 2015; 28(5): E265-9.

12. Tafazzol A, Aref S, Mardani M, Haddad O, Parnianpour M. Epidemiological and biomechanical evaluation of airline baggage handling. Int J OccupSaf Ergon. 2016; 22(2):218-27.

13. Manson NA, McKeon MD, Abraham EP. Transforminal epidural steroid injections prevent the need for surgery un patients with sciatica secondary to lumbar disc herniation: a retrospective case series. 24th Annual North American Spine Society Meeting in San Francisco, California, 2009 Nov 10; San Francisco, California. DOI: 101530/cjs.014611.

14. Riew KD, Park JB, Cho YS, Gilula L, Patel A, Lenke LG et al. Nerve root blocks in the treatment of lumbar radicular pain: A minimum five-years follow-up. J Bone Joint Surg Am. 2006; 8(8):1722-1725.

15. Runu R, Sinha NK, Pai R, Shankar PR, Vijayabhaskar P (2005), Our experience with epidural steroid injections in management of low back pain and sciatica. Kathmandu Univ Med J. 2005; 3(4(12)): 349-354.

Publish in International Archives of Medicine

International Archives of Medicine is an open access journal publishing articles encompassing all aspects of medical science and clinical practice. IAM is considered a megajournal with independent sections on all areas of medicine. IAM is a really international journal with authors and board members from all around the world. 